\title{
Case-control study on feed risk factors for BSE cases born after the feed ban in France
}

\author{
Nathalie JARRIGE ${ }^{\mathrm{a} *}$, Christian DUCROT $^{\mathrm{b}}$, Géraldine CAZEAU $^{\mathrm{a}}$, \\ Eric MORIGNAT ${ }^{\mathrm{a}}$, Claude LA BONNARDIÈRE ${ }^{\mathrm{c}}$, Didier CALAVAS ${ }^{\mathrm{a}}$ \\ ${ }^{a}$ Unité Épidémiologie, AFSSA Lyon, 31 avenue Tony Garnier, 69364 Lyon Cedex 07, France \\ ${ }^{\mathrm{b}}$ Unité d'Épidémiologie Animale, UR346, INRA, Centre de Theix, \\ 63122 Saint-Genès-Champanelle, France \\ ${ }^{\text {c } U n i t e ́ ~ d e ~ V i r o l o g i e ~ e t ~ I m m u n o l o g i e ~ M o l e ́ c u l a i r e s, ~ U R 892, ~ I N R A, ~ C e n t r e ~ d e ~ J o u y-e n-J o s a s, ~}$ \\ 78350 Jouy-en-Josas, France
}

(Received 7 July 2006; accepted 5 January 2007)

\begin{abstract}
In France, after the ban on meat and bone meal (MBM) in cattle feeding in June 1990, cases of Bovine Spongiform Encephalopathy (BSE) have continued to be detected in bovines born after that ban (called BAB cases). A case-control study was therefore carried out to determine the way these cases were contaminated. A multivariate conditional model was built adjusting for the production type of the animals and taking into account the herd size. The results confirmed that feeding cattle with proprietary concentrates was at risk for BSE, with an adjusted odds ratio of 6.8 $(2.5 ; 18.7)$ for the consumption of less or three different proprietary concentrates and $17.6(5.7 ; 54.8)$ for more than three, when comparing with no consumption of proprietary concentrates, considering feeding of bovines before the age of two. The results suggest that cross-contaminations by MBM in bovine concentrates have occurred after 1990. To a lesser extent, on-farm cross-contaminations, i.e. consumption by cattle of feedstuffs initially dedicated to other animals and which could legally contain MBM, have probably also existed, since the presence on farms of poultry fed purchased feed involved an increased risk of BSE with an odds ratio of $1.8(1.1 ; 3.0)$. The use of milk replacers, which often incorporates animal fats, was also at risk with an odds ratio of $1.8(1.0 ; 3.1)$.
\end{abstract}

BSE / cross-contamination / cattle feeding / proprietary concentrates / France

\section{INTRODUCTION}

Bovine Spongiform Encephalopathy (BSE) first described in 1986 [19], is a cattle disease causing lesions in the central nervous system. The large extent of the epidemic during the nineteen-nineties in the United Kingdom, as well as the fact that it was observed progressively in several other countries, have pushed the authorities and researchers to look more closely at the disease. BSE really

\footnotetext{
*Corresponding author: n.jarrige@lyon.afssa.fr
}

became a subject of major interest when a causal link between BSE and a variant of Creutzfeldt-Jakob disease (vCJD) in Humans was evidenced in 1996 [8, 12,24].

Different assumptions have been made to explain cattle infection. Among them, maternal transmission was demonstrated to explain only a very restricted number of cases $[15,22]$. So, the feeding of cattle has always been assumed to be the main way of infection. In fact, for years, meat and bone meal (MBM), which is a by-product of slaughterhouse and fallen stock, was introduced in animal feedstuffs for their protein 
input. Some changes in the process used in feedstuff plants in Great Britain were probably at the origin of the epidemic [20], with the recycling of the agent in cattle proprietary concentrates containing MBM [21].

In order to prevent the risk of BSE in France, animal proteins (except dairy protein, poultry products, fish protein and other sea products) were prohibited from cattle feed in June 1990. That measure was not effective enough to prevent new cases of BSE, since up to May 2006, 847 cases were born after the ban (BAB cases), which represented $85 \%$ of the detected French BSE cases ${ }^{1}$.

From the beginning of the epidemic in France, the National brigade of veterinary and phytosanitary investigations (BNEVP) carried out a detailed investigation on each BSE case, in order to determine the possible origin of the case. From that work and a French report ${ }^{2}$ on animal by-products, three main assumptions were defined to explain the infection of the French BAB cases. First, crosscontaminations of cattle feed with MBM incorporated in monogastric feed could have occurred during their processing in plants, or during their shipment. Second, cross-contaminations on farms could be due to the distribution to bovines of feedstuffs initially dedicated to other species (especially monogastrics) for which MBM was not yet prohibited. Finally, the presence in cattle feedstuffs of some components still authorized for cattle must also be taken into account, particularly certain an-

\footnotetext{
${ }^{1}$ AFSSA, Épidémiosurveillance de l'ESB en France, tableau de bord au 01/05/06, [on line] (2006) http://www.afssa.fr/ftp/afssa/3045830459.pdf [consulted 7 July 2006].

${ }^{2}$ AFSSA, Les risques sanitaires liés aux différents usages des farines et graisses d'origine animale et aux conditions de leur traitement et de leur élimination, [on line] (2001) http://www.afssa.fr/ftp/basedoc/farines.pdf [consulted 7 July 2006].
}

imal fats and calcium phosphates derived from crushed bones. These products could present a risk, because of their composition or possible contact with infected materials on the abattoir chain. These assumptions have not been evaluated so far, and it is of importance to assess retrospectively the role of the incomplete efficiency of the ban of MBM in cattle feed as the cause of the $\mathrm{BAB}$ cases, and to identify the place, whether in the feed mills and/or on the farms, where the contamination of feed occurred. Therefore, a case-control study was carried out to evaluate these assumptions, comparing farming practices in herds that have experienced a BAB BSE case and control herds that had never been affected by the disease.

\section{MATERIALS AND METHODS}

\subsection{Study design}

The case farms were farms in which a BAB BSE case (confirmed by a reference method: histopathology, Western Blot, or immunohistochemistry) was detected between January 1, 2000 and March 28, 2002. In France, the ban on MBM in cattle feed has been in force since June 1990. To take into account the time necessary to run out the stocks - in plants or farms - of cattle feedstuffs manufactured before this date, it was decided to consider as BAB, those cases born after January 1, 1991. The list of the BAB BSE case farms was extracted from the database managed by the AFSSA (Agence Française de Sécurité Sanitaire des Aliments) which is in charge of BSE surveillance monitoring in France.

The study was built with a ratio of one control per case. Controls were farms in which no BSE case had ever been detected. They were randomly selected among the whole cattle farm population listed in the National identification database. Control farms were pair matched with case farms 
on their location (using French administrative Regions as the geographical unit of pairing).

Case and control farms for which documents necessary for the study were missing, either official documents required to check without doubt the inclusion criteria or invoices of feedstuffs purchased all over the studied period, were excluded from the study sample.

On each farm, a bovine was taken into account for the study; it was the BAB case in affected farms, and a bovine randomly selected by the investigator among all the bovines meeting the inclusion criteria on control farms. Control bovines were pair matched with cases on their year of birth, considering years from July 1 of year $\mathrm{N}$ to June 30 of year $\mathrm{N}+1$, in order to stick closer to the farming practices. Taking into account the long incubation period of the disease and the assessment that bovines are contaminated early in life, it was considered that the exposure to any factor during the last two years of life of the bovines were not at risk for being positive at the time of death or slaughter. Consequently the period studied went from the birth of the case until two years before its death. Control bovines could be alive or dead at the time of investigation, but were required to have remained alive during the period of interest of their paired case.

Different exclusion criteria were also taken into account to select the final sample. First, considering the very small number of males affected by BSE (they can be affected but most of them are slaughtered at a young age whereas the incubation period of the disease is long) and the necessity to set up a specific methodology to study them because farming practices are different from those used for females, it was decided to exclude males from the study. In addition, considering that it was not possible to pool data on feeding practices from different farms, cases and con- trols that had not remained on the same farm were also excluded.

Providing that the first $52 \mathrm{BAB}$ cases were used in a preliminary analysis intended to draw the hypotheses on the source of infection, it was not statistically sound to incorporate these cases in the case-control study that was carried out, so we removed those cases from the case population of interest.

\subsection{Data collection}

The data were collected on farms between May 2002 and May 2003 by five investigators specially trained for this work. The inquiries were carried out through an interview of the farmer, based on a detailed questionnaire developed and tested in collaboration with the BNEVP, which had a great experience on this type of inquiry. Data were also collected from the farm records; every invoice concerning the purchase of feedstuffs was photocopied to allow later checking.

The questionnaire first investigated the whole feeding program of the animal and focused on feedstuffs issued from the trade: milk replacers, proprietary concentrates, mineral or vitaminized concentrates (MVC) and raw materials. For feedstuffs provided to bovines, data were collected including the periods of distribution, quantities, shape and delivery formats. The second part of the questionnaire was focused on the other species operations present on the farms. The questions concerned poultry, pigs, rabbits, horses for which MBM were authorized until the end of 2000, as well as sheep and goats for which MBM have been prohibited in France since 1994. Data were collected on the size of these operations and the farming practices such as purchase of feedstuffs and batch rearing (for operations concerned by that practice). The results presented here concern the first two years of life of cases and controls, 
this period being regarded as the more at risk for infection $[3,6,18]$. Data were encoded and stored in an Access database (Microsoft Access 2000, Microsoft Corporation, Redmond, WA, USA).

\subsection{Study sample}

On the basis of the preliminary information (date of birth and death) available in the surveillance database, 253 BAB BSE cases were listed. The farmers were called by phone to verify the inclusion criteria. Finally, 69 cases were excluded for different reasons: the farmer refused to participate $(n=19)$, the feedstuff invoices were totally absent $(n=2)$, the bovine infected did not meet the study criteria in terms of date of birth $(n=4)$ or had moved to another farm during the studied period $(n=44)$. Then for each of the $184 \mathrm{BAB}$ cases included in the study, a control farm was randomly selected among the whole cattle farm population, matching cases and control pairs on the farm Region. The control farms were contacted by phone. If the farm did not meet all the study criteria, another one was randomly selected among the whole cattle farm population in the same Region. The process was continued until a control was found for each case. At the end of the inclusion process, 645 control farms were called by phone, 184 were included in the study and 461 were excluded for different reasons: impossibility to contact the farmer $(n=39)$, farmers were not operating anymore $(n=61)$, farmers refused to participate $(n=171)$, no bovine met the study criteria in the farms $(n=177)$, documents necessary to identify the bovine were missing $(n=5)$ and feedstuff invoices were missing $(n=8)$.

The study sample involved 184 cases and 184 controls. Data relating to the purchase of feedstuffs for poultry and for rabbits were missing for two cases which were consequently excluded with their matched controls. The analyses finally concerned a sample of 182 cases and 182 matched controls.

The farms studied were located in 16 French Regions. The majority of them, $86 \%$ of the cases and $71 \%$ of the controls were dairy bovines. The average size of the studied herds was 67.3 bovines with a median of 59 bovines, considering the number of adult cows, heifers and reproductive males.

\subsection{Analysis}

In order to take into account the matching design, conditional logistic regression models were used [7]. The variables related to the study assumptions are listed in Tables I and II. They were screened for an association with the disease status, case or control, of the bovines with a likelihood ratio test from univariate conditional logistic regressions. Subsequently, variables with a likelihood ratio test of $p<0.20$ were considered for inclusion in a multivariate model.

Tables I and II considered two levels of variables: main variables coded in yes or no considering the sample of 182 case and control pairs with complete data (example: consumption of proprietary concentrates), and variables giving details on the main variable (example: number of proprietary concentrates consumed). To consider the proper effect of variables giving details on a main variable, the univariate analysis was carried out considering only case and control pairs with complete data, and for which the main factor was present. When there was a correlation between two or more of these variables significant in the univariate analysis, only one of them was selected to be tested in the multivariate model. When it was possible, the choice of the variable was made according to the biological point of view, otherwise, the most significant one was chosen. 
Table I. Univariate conditional analysis of potential feed cross-contamination factors, for Born After the Ban (BAB) BSE cases detected in France between January 1, 2000 and March 28, 2002, considering the period between their birth and the age of two.

\begin{tabular}{|c|c|c|c|c|c|c|c|}
\hline \multirow{3}{*}{$\begin{array}{l}\text { Factors } \\
\text { Proprietary concentrate consumption } \\
\left(\text { except } \mathrm{MVC}^{* *} \text { ) }\right.\end{array}$} & \multirow{3}{*}{$\begin{array}{c}\text { No. pairs } \\
182\end{array}$} & \multirow{3}{*}{$\begin{array}{c}\text { Categories } \\
\text { No* }^{*} \\
\text { Yes }\end{array}$} & \multicolumn{2}{|c|}{$\begin{array}{c}\text { No. controls } \\
(\%)\end{array}$} & \multicolumn{2}{|c|}{$\begin{array}{r}\text { No. cases } \\
(\%)\end{array}$} & Likelihood $(p)$ \\
\hline & & & 47 & $(26)$ & 7 & (4) & $1.10^{-9}$ \\
\hline & & & 135 & (74) & 175 & (96) & \\
\hline \multirow{3}{*}{$\begin{array}{l}\text { Age at first consumption of } \\
\text { proprietary concentrates }{ }^{\mathrm{a}} \\
\text { (in months) }\end{array}$} & \multirow[t]{3}{*}{130} & $>6^{*}$ & 15 & (12) & 5 & (3) & \multirow[t]{3}{*}{0.05} \\
\hline & & {$[2-6]$} & 55 & (42) & 58 & (45) & \\
\hline & & ]0-1] & 60 & (46) & 67 & (52) & \\
\hline \multirow{3}{*}{$\begin{array}{l}\text { Total quantity of proprietary } \\
\text { concentrates consumed }^{\text {a }} \text { (in } \mathrm{kg} \text { ) }\end{array}$} & \multirow[t]{3}{*}{130} & ]0-202]* & 40 & (31) & 24 & (18) & \multirow[t]{3}{*}{0.06} \\
\hline & & ] $202-558[$ & 58 & (45) & 65 & (50) & \\
\hline & & $\geqslant 558$ & 32 & (25) & 41 & (32) & \\
\hline \multirow{2}{*}{$\begin{array}{l}\text { Number of proprietary } \\
\text { concentrates consumed }^{\mathrm{a}}\end{array}$} & \multirow[t]{2}{*}{130} & ]0-3]* & 101 & (78) & 81 & (62) & \multirow[t]{2}{*}{$7.10^{-3}$} \\
\hline & & $>3$ & 29 & (22) & 49 & (38) & \\
\hline \multirow{2}{*}{$\begin{array}{l}\text { At least one delivery in bulk } \\
\text { proprietary concentrates }^{\mathrm{a}}\end{array}$} & \multirow[t]{2}{*}{130} & No* & 44 & (34) & 36 & (28) & \multirow[t]{2}{*}{0.26} \\
\hline & & Yes & 86 & (66) & 94 & (72) & \\
\hline \multirow{2}{*}{$\begin{array}{l}\text { Delivery of proprietary } \\
\text { concentrates exclusively in bag }\end{array}$} & \multirow[t]{2}{*}{130} & No* & 88 & (68) & 96 & (74) & \multirow[t]{2}{*}{0.25} \\
\hline & & Yes & 42 & (32) & 34 & (26) & \\
\hline \multirow{2}{*}{$\begin{array}{l}\text { At least one pellet proprietary } \\
\text { concentrate consumed }^{\mathrm{a}}\end{array}$} & \multirow[t]{2}{*}{130} & No* & 5 & (4) & 2 & (2) & \multirow[t]{2}{*}{0.25} \\
\hline & & Yes & 125 & (96) & 128 & (98) & \\
\hline \multirow{2}{*}{$\begin{array}{l}\text { Only pellet proprietary } \\
\text { concentrates consumed }^{\mathrm{a}}\end{array}$} & \multirow[t]{2}{*}{130} & No* & 43 & (33) & 45 & (35) & \multirow[t]{2}{*}{0.78} \\
\hline & & Yes & 87 & (67) & 85 & (65) & \\
\hline \multirow{2}{*}{$\begin{array}{l}\text { At least one flocculated proprietary } \\
\text { concentrate consumed }^{\mathrm{a}}\end{array}$} & \multirow[t]{2}{*}{130} & No* & 105 & (81) & 105 & $(81)$ & \multirow[t]{2}{*}{1} \\
\hline & & Yes & 25 & (19) & 25 & (19) & \\
\hline Milk replacer consumption & 182 & No* & 125 & (69) & 89 & (49) & $2.10^{-4}$ \\
\hline & & Yes & 57 & (31) & 93 & (51) & \\
\hline Age at first consumption of milk & 26 & $\geqslant 12^{*}$ & 8 & (31) & 9 & (35) & 0.74 \\
\hline replacer ${ }^{b}$ (in days) & & ]0-12[ & 18 & (69) & 17 & (65) & \\
\hline Number of milk replacers & 26 & ]0-1]* & 20 & (77) & 23 & (88) & 0.31 \\
\hline consumed $^{\mathrm{b}}$ & & $\geqslant 2$ & 6 & (23) & 3 & (12) & \\
\hline MVC consumption & 182 & No* & 28 & (15) & 25 & (14) & 0.66 \\
\hline & & Yes & 154 & $(85)$ & 157 & $(86)$ & \\
\hline Raw material consumption (except & 182 & No* & 112 & $(62)$ & 120 & $(66)$ & 0.38 \\
\hline hay and $\left.\mathrm{MVC}^{* *}\right)$ & & Yes & 70 & (38) & 62 & (34) & \\
\hline
\end{tabular}

* Reference category.

** Mineral or vitaminized concentrates.

${ }^{a}$ Only pairs for which both the case and the control consumed at least one proprietary concentrate were considered.

${ }^{\mathrm{b}}$ Only pairs for which both the case and the control consumed at least one milk replacer were considered.

The multivariate conditional model was built using the technique of manual process of backward elimination. The effect of each variable was tested by the Wald test. The variables with $p>0.05$ were removed one at a time from the model if their removal did not dramatically alter the odds ratio estimates of the other variables. If the variation of the odds ratio estimates of the other variables was less than $10 \%$, 
Table II. Univariate conditional analysis of potential on farm cross-contamination factors for Born After the Ban (BAB) BSE cases, detected in France between January 1, 2000 and March 28, 2002, considering the period between their birth and the age of two.

\begin{tabular}{|c|c|c|c|c|c|c|c|}
\hline Factors & No. pairs & Categories & No. c & nntrols & No. & ases & Likelihood $(p)$ \\
\hline & & & & (\%) & (P) & (\%) & \\
\hline Presence of poultry & 182 & No* & 72 & (40) & 57 & (31) & 0.10 \\
\hline & & Yes & 110 & (60) & 125 & (69) & \\
\hline Purchase of feed for poultry ${ }^{a}$ & 76 & $\mathrm{No}^{*}$ & 19 & (25) & 12 & (16) & 0.12 \\
\hline & & Yes & 57 & (75) & 54 & (84) & \\
\hline Number of poultry ${ }^{\mathrm{a}}$ & 67 & ]0-7665]* & 23 & (34) & 20 & (30) & 0.82 \\
\hline (in animal $\times$ day-year) & & ]7665-20075] & 25 & (37) & 27 & (40) & \\
\hline & & $>20075$ & 19 & (28) & 20 & (30) & \\
\hline Breeding in batch of poultry ${ }^{\mathrm{a}}$ & 74 & No* & 66 & (89) & 62 & (84) & 0.34 \\
\hline & & Yes & 8 & (11) & 12 & (16) & \\
\hline Presence of rabbits & 182 & No* & 133 & (73) & 120 & (66) & 0.14 \\
\hline & & Yes & 49 & (27) & 62 & (34) & \\
\hline Purchase of feed for rabbits ${ }^{b}$ & 17 & $\mathrm{No}^{*}$ & 8 & (47) & 5 & (29) & 0.25 \\
\hline & & Yes & 9 & (53) & 12 & (71) & \\
\hline Number of rabbits ${ }^{b}$ & 13 & ]0-6935]* & 5 & (38) & 2 & (15) & 0.07 \\
\hline (in animal $\times$ day-year) & & ]6935-12775] & 7 & (54) & 7 & (54) & \\
\hline & & $>12775$ & 1 & (8) & 4 & (31) & \\
\hline Presence of pigs & 182 & $\mathrm{No}^{*}$ & 133 & (73) & 129 & (71) & 0.63 \\
\hline & & Yes & 49 & (27) & 53 & (29) & \\
\hline Presence of goats & 182 & $\mathrm{No}^{*}$ & 174 & (96) & 169 & (93) & 0.25 \\
\hline & & Yes & 8 & (4) & 13 & (7) & \\
\hline Presence of sheep & 182 & $\mathrm{No}^{*}$ & 163 & (90) & 168 & (92) & 0.38 \\
\hline & & Yes & 19 & (10) & 14 & (8) & \\
\hline Presence of horses & 182 & $\mathrm{No}^{*}$ & 163 & (90) & 169 & (93) & 0.24 \\
\hline & & Yes & 19 & (10) & 13 & (7) & \\
\hline
\end{tabular}

* Reference category.

${ }^{a}$ Only pairs for which both the case and the control had poultry and a complete data set were considered.

${ }^{b}$ Only pairs for which both the case and the control had rabbits and a complete data set were considered.

the variable was definitively removed from the final model.

The model systematically incorporated the herd size through an offset defined as the logarithm of the herd size [16]. The production type (dairy versus beef) was also considered for inclusion in the multivariate model as a potential confounder. The results were presented as odds ratios (OR) and 95\% confidence intervals (CI). The data were analyzed with Statis- tical software S-Plus (S-Plus, Professional release 6.2, Mathsoft, Inc., Seattle, WA, USA).

\section{RESULTS}

According to the univariate analysis on the type of purchase of feed for cattle (Tab. I), two main variables were significant: the consumption of milk replacer, which was therefore introduced in the final model, and the consumption of proprietary 
concentrates. Concerning the consumption of proprietary concentrates, three-order variables providing details (age at first consumption, quantity consumed, and number of different commercial concentrates used) were also significant. Because of the strong correlation between these four variables it was not possible to introduce them together in a multivariate model. For that reason, the most significant one, i.e. the number of proprietary concentrates consumed, was selected for the multivariate analysis. In order to work on the whole data sample ( $n=182$ pairs), a class was added to the variable, taking into account the farms in which no concentrate was consumed by the bovine. That class was next considered as the reference class in the model. Concerning the univariate analysis on the presence and type of other species on the farms (Tab. II), the presence of poultry was retained, as well as the use of poultry feed in these operations, the relationship between these two variables and BSE being similar (respectively $p=0.10$ and $p=0.12$ ). Moreover, considering that the risk was similar for farms without poultry and farms with poultry but with no purchase of feedstuffs for that species, a dichotomous variable (purchase of feedstuffs for poultry: yes or no) combining the information for the whole sample of farms ( $n=182$ pairs) was built to be tested in the multivariate model.

Another retained univariate result was the presence of rabbits and the size of the rabbit operations on farms. Because of a higher link between the size of rabbit operation and BSE compared to the presence of rabbits, the size of the rabbit operation was introduced in the multivariate model as a four-class variable, considering as reference class the farms without rabbits.

The multivariate conditional model (Tab. III), adjusted on the cattle production type and taking the herd size as an offset into account, showed a significant relationship between the status of bovine, case or control, and the consumption of proprietary concentrates before the age of two. The odds ratios were $6.8(2.5 ; 18.7)$ for three or less different concentrates consumed and $17.6(5.7 ; 54.8)$ for more than three, when comparing with no consumption of proprietary concentrates. Two other variables showed a significant effect: the consumption of a milk replacer with an odds ratio of $1.8(1.0 ; 3.1)$, and the purchase of feedstuffs for poultry with an odds ratio of $1.8(1.1 ; 3.0)$.

\section{DISCUSSION}

Despite the ban on MBM for cattle feed in 1990 in France, hundreds of BSE cases have been detected in bovines born after this date. It was then hypothesized that the measure has not been completely effective to prevent new infections. A case-control study was therefore undertaken with the aim to clear up the processes at the origin of the BAB cases.

The study design was scrupulously worked out to avoid possible bias. Before the beginning of the statistical analysis, the status of the control was checked. It was confirmed that no case of BSE was detected in control farms since the study sampling. As it has already been shown by geographical analysis, the BSE cases were not randomly distributed in France [1]; this is the reason why cases and controls were matched on their geographic location to take into account the spatial heterogeneity of the risk. In the same way, it was noticed that the farming practices, or the manufacturing processes in feed plants could have changed over time. So, in order to define a study sample in which cases and controls have been submitted to a global comparable level of risk, they were matched on their birth cohort. The production type of cattle, dairy or beef, was also considered as a potential confounding factor [13,23]. Since the farmer practices concerning the cattle feeding were related 
Table III. Multivariate conditional logistic regression model of potential risk factors for Born After the Ban (BAB) BSE cases, detected in France between January 1, 2000 and March 28, 2002, considering the period between their birth and the age of two, the herd size being taken into account as an offset ( $n=182$ pairs).

\begin{tabular}{lccc}
\hline Factors & Categories & OR** & $95 \%$ CI \\
\hline Production type & Beef* & - & - \\
& Dairy & 1.0 & $0.5-2.1$ \\
No. of proprietary concentrates consumed & $0^{*}$ & - & - \\
& $10-3]$ & 6.8 & $2.5-18.7$ \\
Consumption of milk replacer & $>3$ & 17.6 & $5.7-54.8$ \\
& No* & - & - \\
Purchase of feedstuffs for poultry & Yes & 1.8 & $1.0-3.1$ \\
& No* & - & - \\
& Yes & 1.8 & $1.1-3.0$ \\
\hline
\end{tabular}

* Reference category.

** OR: odds ratio; CI: confidence interval.

to the production type, it was decided not to pair cases and controls on this factor to avoid a possible overmatching bias but to consider it as a potential confounder in the model. Finally, it was shown through the fitted multivariate model, that the type of cattle production was not any more significant, when the other risk factors were also incorporated in the model. This tends to prove that the effect of the production type was due to the factors related to feedstuff consumption. Concerning the herd size, it was introduced in the final model as an offset, considering that large herds have a statistically greater chance to have a case than small ones [23] and that farmer practices also depend on the herd size.

The process of inclusion of the bovines in the sample study was made so as to know the reason of each exclusion. On the contrary to what could have been awaited, the rate of refusal was more important for controls than for cases. The reasons to refuse to participate in the study have not been collected. Nevertheless, some assumptions can be formulated: first of all, a real practical impossibility to take part in the investigation which could last from half to a complete day, but it was noted that the proportion of monthly refusals was stable and therefore not linked to farmer workload; secondly, the fears of the farmers not linked with their individual practices (due to the general climate of suspicion since the discovery of the relationship between BSE and VCJD or to the heavy regulation measures taken when a case is discovered on a farm and which were in force at the time of the study, i.e. the culling of the whole herd at this time); finally, the fears of the farmers due to the existence of practices at risk. Knowing that certain infection assumptions were due to farmer practices, i.e. feeding cattle with feedstuffs dedicated to other species, this last situation could introduce a bias in the results by increasing the odds ratios, if some farmers selected as potential controls refused to participate because they applied these practices. However, it was not possible to determine which part of the farmers was in that case. The bovines that had moved from the farm during the study period were also excluded from the final sample, because it was not possible to compile data coming from two or more distinct farms. These exclusions concerned only one control and 44 cases for which there is no reason to think they had particular practices; so their exclusion should not affect the results. Concerning 
the 61 farms (only controls) which were not operating anymore at the time of the inquiry, the situation was only the reflect of the poor update of the database used to select the controls, which contained obviously erroneous data. Consequently, these exclusions could not bias the results.

In a more general way, the retrospective collection of data remains an undeniable difficulty for this kind of study. Because of the long incubation period of BSE, which is around five years $[3,6,14]$, the inquiries took place up to ten years after the birth of the case or control. This explains why some farms ( 2 cases and 13 controls contacted for the study) did not preserve invoices or identification documents referring to bovines, sometimes already dead. Considering that the inquiries required a great effort of memory from the farmers, the detailed checking of the feedstuff invoices was a way to alleviate that difficulty. The farmers that did not have these documents were then excluded from the study. For the reasons evocated above, their exclusion was not related to the risk factors under study.

The major result of the study confirms the strong relationship between consumption of proprietary concentrates and BSE, and hence the possibility of contamination of these feedstuffs infected by MBM. This result is in line with those first demonstrated in the precedent case-control study in 1992 in the UK [21] realized before the ban of MBM in Great Britain. For bovines consuming proprietary concentrates the number of different proprietary concentrates consumed is also linked to the risk of BSE, with an OR of 6.8 for less than three concentrates before the age of two and of 17.6 for more than three. This last result suggests that the higher the number of different proprietary concentrates consumed, the higher the risk was to resort to a firm which had not taken relevant measures to avoid the contamination of cattle feedstuffs by MBM.
In fact, several practices in use in animal feed plants at that time could explain the contamination of proprietary concentrates by MBM. The risk of crosscontamination was particularly of concern in the plants producing both bovine and other species feedstuffs (sheep and goats for which MBM were still legal until 1994 and monogastrics until the end of 2000). Such plants often used a single equipment to manufacture their different products, and MBM could have remained stuck along the different equipments in contact with the feedstuffs (various pipes, mixing or pressing-machine, storage cells etc.). MBM can thus be unexpectedly incorporated in cattle feedstuffs manufactured after a feedstuff containing MBM. For technical or commercial reasons, feedstuff factories need to manage manufacture wastes or returns from customers (feedstuffs not consumed or out-of-date) initially dedicated to different species. These products possibly containing MBM could have been introduced as raw material in new proprietary concentrates, mainly for young ruminants, which are not very sensitive to the type of compound. Finally, accidental or voluntary incorporations of MBM directly in cattle feedstuffs could have also occurred, particularly in plants in which the compound formula were not controlled by data processing. In order to study the contamination of bovine proprietary concentrates during their shipment, inside the truck, the assumption was based on a possible contamination of cattle feedstuffs by other species feedstuffs delivered in bulk. The study showed that the shipment of feedstuffs exclusively in bags was not significantly protective and that the delivery of at least one bovine feedstuff in bulk did not represent a significant risk. The results did not highlight either any risk for the consumption of purchased raw materials, for which a significant connection with the status case or control would have been another element to support the 
assumption of a contamination during the shipment.

Purchase of MVC was considered apart from other proprietary concentrates. These products would not have been exposed to the same risk of contamination. They are produced in specific plants that do not use MBM, and their usual feeding form as blocks (salt stones, lick stones) did not favor a risk of contamination during their shipment. Nevertheless, information on the use of MVC was collected to assess the potential role of dicalcic phosphates derived from crushed bones, which could have been included in these products. The MVC effect was not highlighted in the results of the study and therefore their implication as a source of BSE would have been extremely marginal if it existed.

Concerning the role of animal fats (particularly tallow derived from ruminant animals) in BSE infections, only few data were available. Some studies have shown the liposolubility of prions $[4,5]$, but there was no evidence that fat would constitute a BSE risk. However, along the process at the slaughterhouse, fat could have been contaminated with protein impurities by contact with other infectious materials ${ }^{3}$ Animal fats are frequently incorporated into cattle feedstuffs for their nutritional and/or technical interest. Apart from proprietary concentrates, the risk could also concern milk replacers [17], which are made of dehydrated and defatted cow milk in which animal fats, most of the time tallow, or vegetable fats are reincorporated. The relationship between the risk of BSE and milk replacer consumption was already highlighted at $p<10^{-4}$ by a univariate test in another recent epidemiological

\footnotetext{
${ }^{3}$ European Commission, Revised Opinion and Report of the Scientific Steering Committee on the Safety of Tallow Obtained from Ruminant Slaughter By-products, [on line] (2001) http:// europa.eu.int/comm/food/fs/sc/ssc/out228_en.pdf [consulted 7 July 2006].
}

study [9-11]. In our study, the consumption of milk replacers by bovines appeared to be at risk for BSE. However, it is difficult to differentiate the specific role of milk replacers among the other risk factors for two main reasons: (i) the consumption of milk replacers depends on the production type and is quasi exclusively consumed by dairy calves; (ii) most of the farmers that provided milk replacers to their calves, also fed them with proprietary concentrates, according to the study data. That situation was taken into account as much as possible by the use of a multivariate model.

Apart from milk replacers, animal fats were also used in proprietary concentrates to agglomerate them according to various forms such as pellets or flakes. To evaluate a possible effect of animal fats in proprietary concentrates, some attempts were also made to estimate the effect of their physical form. Nevertheless, no difference was observed in our study whatever the physical form of the feedstuff.

The cross-contamination on the farm, i.e. the consumption by cattle of feedstuffs initially dedicated to other species, and which could contain MBM, was tested. Taking into account the strong risk of bias in the farmer's answers, because their responsibility was directly engaged on that question, it was not possible to ask them directly if they had or not given other species feedstuffs to the bovines. To prevent this bias, the choice was made to collect only factual data on the presence of other species on the farm, as well as the size of these operations, the purchase of dedicated feedstuffs and the breeding in batches, information which themselves were not likely to blame the bovine farmers. Adjusting for the other risk factors, the odds ratios related to the purchase of feedstuffs for poultry was significant 1.8 . Considering that MBM was frequently included in poultry feedstuffs before the 2000 ban, this result suggests that cross-contaminations really occurred on farms after 1990. 
Concerning pigs, a former geographical study [2] has shown that the density of pigs in a given area was significantly associated with an increased risk of BSE, with an estimate increase of $2.4 \%$ per 10000 pigs. This relationship was not confirmed in our case-control study, since no significant relation has been shown in the univariate analysis between the presence of pigs on the farm and BSE. It was also checked that the number of pigs in the operation was not linked with the risk of BSE. These two conflicting results need further studies. One explanation would be that the pig associated risk is due to crosscontaminations during the feed processing in plants whereas there were no contamination on farms between cattle and pig operations in mixed farms. Finally, for the other species, sheep, goats or horses, their presence and consequently the feedstuffs purchased for these species did not appear at risk for BSE.

To conclude, the analysis confirmed that the purchase of cattle concentrates was at risk for BSE, and showed an increased risk when the bovines consumed more than three different proprietary concentrates. To a lesser extent, consumption of milk replacers as well as the presence on the farm of poultry fed with purchased feed, appeared to be at risk. On the one hand, cross-contamination has probably occurred on farms, by feeding monogastric feedstuffs, particularly dedicated to poultry, to bovines. On the other hand, the results suggest that some feed manufacturers did not implement sufficient measures to avoid cross contamination of cattle feedstuffs by MBM, by adapting their equipment or practices. In addition, it would be of the utmost interest to get a better knowledge of the contamination process, to carry out complementary investigations in feed plants, in order to obtain more details on practices that were in force in the nineteennineties.
The main interest of the study was to assess the efficiency of the control measures that have been undertaken; here it was demonstrated that the stringent and expensive measures taken in France in 1990 have not been $100 \%$ sufficient to control the disease and that some additional measures were necessary. It is admitted at the European level that a ruminant to ruminant MBM ban has not been efficient enough to control BSE; this paper gives some evidence on this topic. In the same way, it is also of some interest for countries that might have to deal with such a situation. Finally, apart from any other consideration, the study provides precise descriptive data on feeding of bovines from a consistent sample of farms in France and constitutes in itself a useful database on cattle farming practices in the field.

\section{ACKNOWLEDGEMENTS}

The authors would like to thank the 'Direction Générale de l'Alimentation' from the Ministry of Agriculture especially Daniel Lafon and Benoît Thiebot from the 'Brigade Nationale d'Enquêtes Vétérinaires et Phytosanitaires' for their advice, as well as Patrick Gasqui for his useful advice on statistics. The authors gratefully acknowledge all the farmers who were involved in the study, the five investigators Nicolas Bonnet, Nathalie Goarin, Martine Lefèvre Hartheiser and Régis Moneger who collected the data on farms and the AFSSA Epidemiology Unit members: Valérie Cespedes, Bénédicte Lafanechère, Christelle Swiathowski and Jean-Luc Vinard for their technical help. The study was funded within the framework of the "Groupement d'Intérêt Scientifique : Infections à Prions".

\section{REFERENCES}

[1] Abrial D., Calavas D., Jarrige N., Ducrot C., Spatial heterogeneity of risk of BSE in France following the ban of meat and bone meal in cattle feed, Prev. Vet. Med. (2004) 67:69-82. 
[2] Abrial D., Calavas D., Jarrige N., Ducrot C., Poultry pig and the risk of BSE following the feed ban in France - Spatial analysis, Vet. Res. (2005) 36:615-628.

[3] Anderson R.M., Donnelly C.A., Ferguson N.M., Woolhouse M.E.J., Watt C.J., Udy H.J., MaWhinney S., Dunstan S.P., Southwood T.R.E., Wilesmith J.W., Ryan J.B.M., Hoinville L.J., Hillerton J.E., Austin A.R., Wells G.A.H., Transmission dynamics and epidemiology of BSE in British cattle, Nature (1996) 382:779-788. Erratum in: Nature (1997) 386:302.

[4] Appel T.R., Riesner D., von Rheinbaben F., Heinzel M., Safety of oleochemical products derived from beef tallow or bone fat regarding prions, Eur. J. Lipid Sci. Technol. (2001) 103:713-721.

[5] Appel T.R., Wolff M., von Rheinbaben F., Heinzel M., Riesner D., Heat stability of prion rods and recombinant prion protein in water, lipid and lipid-water mixtures, J. Gen. Virol. (2001) 82:465-473.

[6] Arnold M.E., Wilesmith J.W., Estimation of the age-dependent risk of infection to BSE of dairy cattle in Great Britain, Prev. Vet. Med. (2004) 66:35-47.

[7] Breslow N.E., Day N.E., Statistical methods in cancer research. The analysis of casecontrol studies, Vol. 1, Lyon, France, IARC Sci. Publ. (1980) 32:5-338.

[8] Bruce M.E., Will R.G., Ironside J.W., McConnell I., Drummond D., Suttle A., McCardle L., Chree A., Hope J., Birkett C., Cousens S., Fraser H., Bostock C.J., Transmission to mice indicate that "new variant" CJD is caused by the BSE agent, Nature (1997) 389:498-501.

[9] Calavas D., Jarrige N., Ducrot C., Potential risk factors for BSE, Vet. Rec. (2006) 158:743-744.

[10] Clauss M., Sauter-Louis C., Potential risk factors for BSE, Vet. Rec. (2006) 158:744.

[11] Clauss M., Sauter-Louis C., Chaher E., Pottgiesser C., Goebel S., Selhorst T., Wichmann H.-E., Klee W., Kienzle E., Investigations of the potential risk factors associated with cases of bovine spongiform encephalopathy in Bavaria, Germany, Vet. Rec. (2006) 158:509-513.

[12] Collinge J., Sidle K.C.L., Meads J., Ironside J., Hill A.F., Molecular analysis of prion strain variation and the aetiology of "new variant" CJD, Nature (1996) 383:685-690.

[13] Ducrot C., Roy P., Morignat E., Baron T., Calavas D., How the surveillance system may bias the results of analytical epidemiological studies on BSE: prevalence among dairy versus beef suckler cattle breeds in France, Vet. Res. (2003) 34:185-192.

[14] Ferguson N.M., Donnelly C.A., Woolhouse M.E.J., Anderson R.M., The epidemiology of BSE in cattle herds in Great Britain. II. Model construction and analysis of transmission dynamics, Philos. Trans. R. Soc. Lond. B Biol. Sci. (1997) 352:803-838.

[15] Hoinville L.J., Wilesmith J.W., Richards M.S., An investigation of risk factors for cases of bovine spongiform encephalopathy born after the introduction of the feed ban, Vet. Rec. (1995) 136:312-318.

[16] La Bonnardière C., Bonaiti B., Abrial D., Gasqui P., Calavas D., Ducrot C., Barnouin J., Milk yield, age at first calving, and the risk of BSE: an analysis at the farm level in France, Prev. Vet. Med. (2007) 78:67-78.

[17] Paisley L.G., Hostrup-Pedersen J., A quantitative assessment of the risk of transmission of bovine spongiform encephalopathy by tallow-based calf milk-replacer, Prev. Vet. Med. (2004) 63:135-149.

[18] Supervie V., Costagliola D., The unrecognised French BSE epidemic, Vet. Res. (2004) 35:349-362.

[19] Wells G.A.H., Scott A.C., Johnson C.T., Gunning R.F., Hancock R.D., Jeffrey M., Dawson M., Bradley R., A novel progressive spongiform encephalopathy in cattle, Vet. Rec. (1987) 121:419-420.

[20] Wilesmith J.W., Ryan J.B.M., Atkinson M.J., Bovine spongiform encephalopathy: epidemiological studies on the origin, Vet. Rec. (1991) 128:199-203.

[21] Wilesmith J.W., Ryan J.B.M., Hueston W.D., Bovine spongiform encephalopathy: casecontrol studies of calf feeding practices and meat and bonemeal inclusion in proprietary concentrates, Res. Vet. Sci. (1992) 52:325-331.

[22] Wilesmith J.W., Wells A.H., Ryan J.B.M., Gavier-Widen D., Simmons M.M., A cohort study to examine maternally-associated risk factors for bovine spongiform encephalopathy, Vet. Rec. (1997) 141:239-243.

[23] Wilesmith J.W., Ryan J.B.M., Stevenson M.A., Morris R.S., Pfeiffer D.U., Lin D., Jackson R., Sanson R.L., Temporal aspects of the epidemic of bovine spongiform encephalopathy in Great Britain: holdingassociated risk factors for the disease, Vet. Rec. (2000) 147:319-325.

[24] Will R.G., Ironside J.W., Zeidler M., Cousens S.N., Estibeiro K., Alperovitch A., Poser S., Pocchiari M., Hofman A., Smith P.G., A new variant of Creutzfeldt-Jakob disease in the UK, Lancet (1996) 347:921-925. 